\title{
The Research of Teaching Resource Library Construction under the Guidance of Cognitive Psychology
}

\author{
NI FengKun ${ }^{1, a}$ \\ ${ }^{1}$ Yellow River Conservancy Technical Institute, Kaifeng 475004, China \\ a nifengkun@yeah.net
}

Keywords: Teaching Resource, Cognitive Psychology, Resources Management

\begin{abstract}
Through the network learning has become a new kind of study way, the open network education resource to cultivate international competitive talents in the new century to create the most favorable conditions. Cognitive psychology theory in the construction of teaching resource plays a very important role in guiding. In the interpretation and repository construction, on the basis of related theory of cognitive psychology, from the perspective of cognitive psychology, puts forward the problems that should be paid attention to in the construction of teaching resource database, and to guide the construction of teaching resource database.
\end{abstract}

\section{Introduction}

In the tide of a new round of education informatization, through the network learning has become a new kind of study way, the open network education resource to cultivate international competitive talents in the new century to create the most favorable conditions. Schools are teaching as the center, the purpose of the teaching resource construction is supported by the application in the teaching of teaching reform, improve the teaching quality. But in the context of social education informatization, teaching resource construction is one of the major problems facing the blind pursuit of material lot, weight is not heavy, it violates the people's cognitive laws, so the repository construction first needs the guidance of scientific theory [1].

Cognitive psychology is based on information processing as the core of psychology. It uses information processing point of view to study cognitive movement, research scope mainly includes the sense perception, attention, representation, learning, memory, thinking and language or cognitive psychological process. The current information technology environment, the theory of cognitive psychology teaching resource database construction has direct guiding significance. This paper discusses the theory of cognitive psychology related to the influence of the teaching resource construction, and from the perspective of cognitive psychology in the current database construction process should pay attention to some problems.

\section{Summary of cognitive psychology}

The put forward and development of cognitive psychology is based on psychology and traditional western philosophy also has a connection with cognitive psychology. Cognitive psychologists emphasize the role of knowledge, believe that knowledge is the main factor to human behavior. In on the basis of philosophy and psychology, and after the rule of behavior psychology, cognitive psychology gradually. Cognitive psychology since it was born for its research there are many different points of view, the position and way [2]. In numerous viewpoints to information processing point of view for the mainstream research, cognitive process, think is cognitive information processing, and who is an information processing system, including sensory input in the system during the process of transformation, processing, storage and use. The cognitive process is decomposed into a series of stages, each stage is the input of information for a specific operation unit, the reaction product, is this a series of phases and operation of the cognitive system between all parts of the are connected with each other. Information processing in what stage and information 
in the form of what expression in human psychology is the basic problem of information processing view [3].

Cognitive psychology attempts to unify the whole cognitive process, people's attention, perception, memory and thinking in cognitive phenomenon such as are intertwined. Cognitive psychologists believe that for a set of phenomena of understanding helps to explain the phenomenon of another group. Are interdependent relationship between the cognitive processes, so are likely to find the human cognitive process unified processing mode [4]. Cognitive psychology is not only to the people to know the process of unification, but also contact the areas of general psychology, with studies from the perspective of cognition and mood change, motivation and personality development, etc. Cognitive psychology, developmental psychology and social psychology point of view also physiological psychology and engineering psychology, and other fields has been varying degrees of application.

\section{Cognitive psychology theory method research for teaching resource library}

Teaching resources and teaching resource management system are two major part of teaching resource, both for teaching resource construction plays an important role. Developed on the basis of cognitive psychology of cognitive learning theory is the result of interaction with the environment. Learning is not a simple passive learners to external stimuli to make adaptive response; But regard learning as learners according to their own attitude, needs, interests, hobbies, to use their original cognitive structure, on the current information voluntarily provided by external stimuli, selective information processing [5]. In the teaching resource construction of learning environment, teaching resources is the major factor, the end of the change of the learners' psychological or resource itself; Teaching resource management system is the external conditions, its present and also determines the learning effective. So any one-sided emphasis on the construction of teaching resources in the reality, or only pay attention to the development of teaching resource management system will greatly reduce the use effect of the repository. The structure of the guidance method is shown in figure 1.

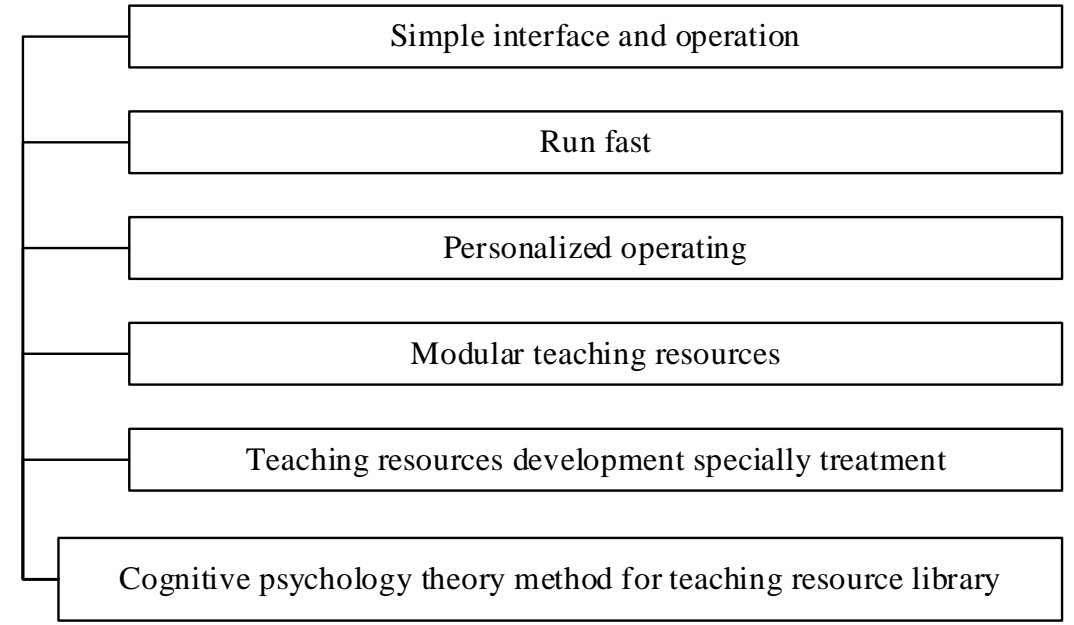

Figure 1. The structure of the guidance of cognitive psychology theory method

Under the guidance of cognitive psychology, the teaching resource users of the system is divided into two categories, category for ordinary users, another kind is the administrator user, these two types of user login repository after the system will enter the different user space for different operation. Administrator space including classification management, resource management, user management database system management functions, normal user space is confined to the resources retrieval, browse, upload, download, and so on. The flow chart of the teaching resource library under the guidance of cognitive psychology is shown in figure 2 . 


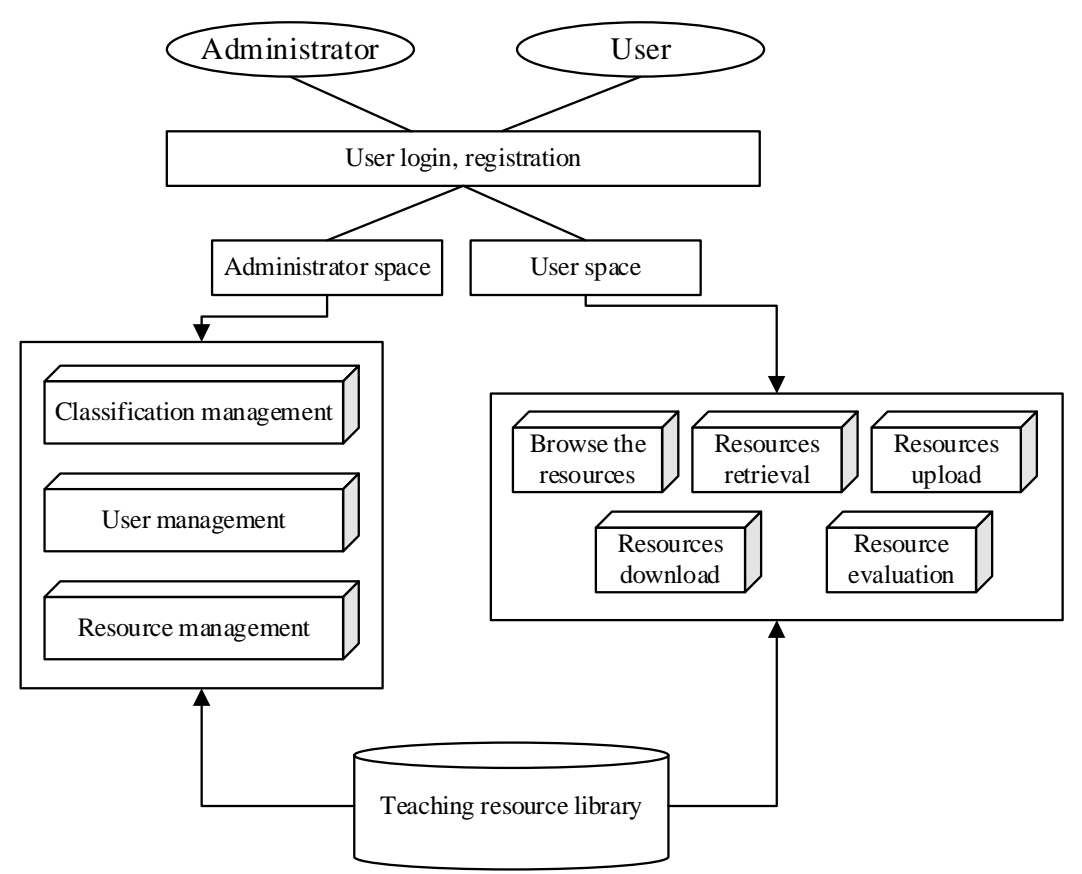

Figure 2. Access process of the teaching resource library system

\section{The teaching resource library design under the guidance of cognitive psychology}

The existing teaching resource database construction item through the top design, the advanced technical support, open overall operation management, the Internet operation way, integrate social teaching resources, integration of the professional quality of teaching resources. A perfect teaching resource construction should be from the resource library, navigation, resources retrieval, resource management, user management, evaluation center, and so on several aspects. On the basis of professional teaching standards, high-end skills applied talents training goal, the students' quality, professional ability and the comprehensive consideration of sustainable development, the introduction of industry, enterprise technical standard, reflect the demands of post group, pay attention to the latest changes in the field of clingy. Construction of teaching resource, specification should be the basic requirements of teaching, realize the high share of teaching resources as the fundamental goal. To meet the need of students' autonomous learning, this paper built under the guidance of cognitive psychology, the teaching resource, the structure diagram is shown in figure 3.

Physical layer is the educational resources. The bottom of the cloud platform provides the basic hardware resources, including computers, servers, storage, databases, network equipment, computers and other educational resources in the cloud platform hardware requirements low, distributed technology and virtualization technology will provide a super form a distributed computer cluster cloud computing and storage operations.

Virtual Manager is a resource on the second floor Education Cloud platform. Through virtualization technology, a lot of the same type of physical layer resources constitute a resource pool, with the utilization of a similar structure or structures to eliminate physical hardware limitations, reducing hardware management complexity, increase hardware resources, to effectively control costs and ensure information resource sharing system scalability, the upper pavilion is intended to provide resources.

Things management is the core part of the overall application management cloud platform educational resources, by the application of the monitoring, user management, tasks, principles, resource management, log management, and other main function is to use cloud computing technology will be presented together with the integration of resources resource layer. Virtual organization pavilion app phone.

Services layer is to achieve educational resource platform, and mainly by the resource management and communications platform composed of two parts, the main function is to provide 
services and solutions to achieve view, download resources, resource audit, resource publishing, and educational resources management functions and information consulting, announcement, information exchange.

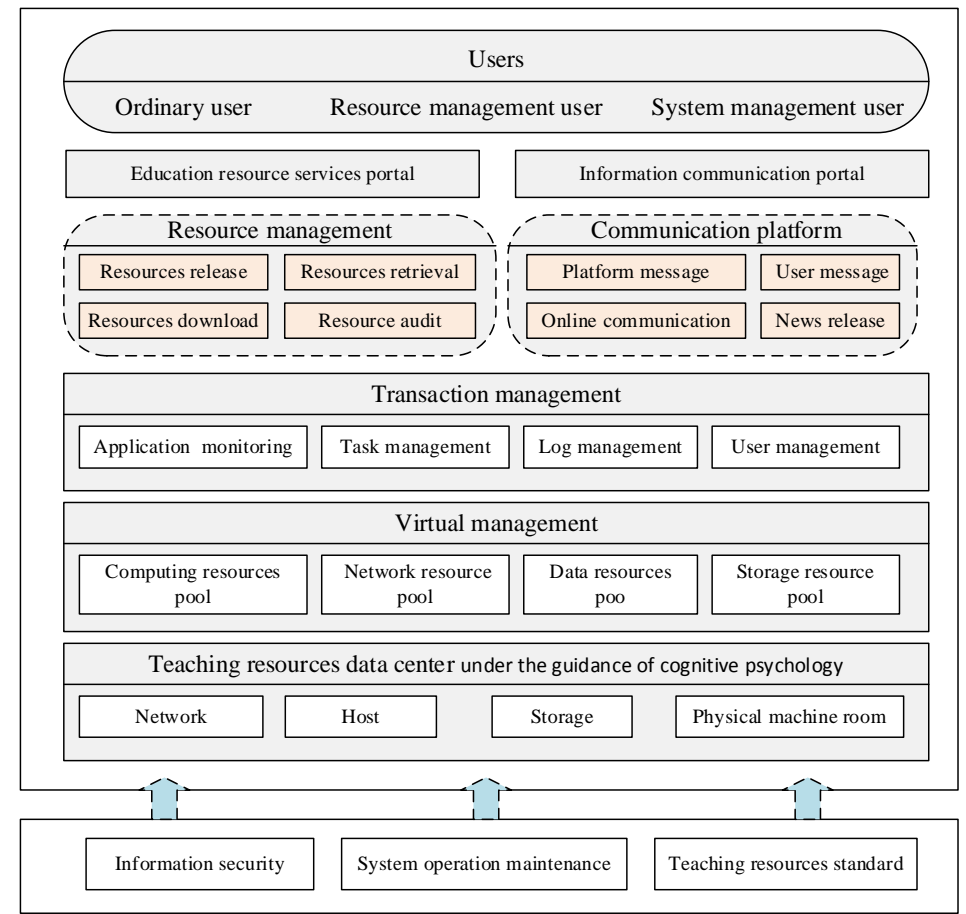

Figure 3. The teaching resource library structure model under the guidance of cognitive psychology

\section{Conclusion}

With the rapid development of Internet, network information rapidly changing, people expect more and more demand for accurate information, the old, slow, blind information service mode has far cannot meet the demand of the rapid and accurate for the information. Teaching database is mainly on the basis of actual teaching efficiency, the purpose is to serve the teachers teach, service to the students to learn, in the service of mutual learning between teachers and students, service the development of students. Starting from this basis, the teaching resource construction, besides should follow the scientific theoretical guidance to the actual situation of adjust measures to local conditions, according to the unit in the integrated equipment, the environment, factors such as operation ability is poised between teachers and students, with the school characteristics construction of teaching resource database. This paper proposes a teaching resource database model based on the theory of cognitive psychology, the scientific utilization of teaching resources is of great significance.

\section{References}

[1] C. Jarvis, and J. Dickie: Journal of Geography in Higher Education, Vol. 34 (2010) No.2, p.173.

[2] Y. Imai: The Modern Language Journal, Vol. 94 (2010) No.2, p.278.

[3] N Braisby, and A Gellatly: Cognitive psychology, Oxford University Press, 2012.

[4] F.D. Betoret: Educational Psychology, Vol.29 (2009) No.1, p.45.

[5] J. Baumert, M. Kunter, and W. Blum: American Educational Research Journal, Vol. 47 (2010) No.1, p.133. 